\title{
Analisis Hasil Pengukuran Bidang Tanah Menggunakan Teknologi CORS-NTRIP dan PPP
}

\author{
G. A. JESSY KARTINI, A. SALMAN RAHMANI, REZA PALEVI \\ Jurusan Teknik Geodesi, \\ FTSP - Institut Teknologi Nasional, Bandung \\ Email: ayujessy@gmail.com
}

\begin{abstract}
ABSTRAK
Kebutuhan akan pemanfaatan tanah dan ruang semakin meningkat setiap tahun. Untuk mengendalikan kebutuhan tersebut maka diperlukan penyediaan sertifikat bidang tanah. Pengadaan sertifikat ini terkait erat dengan metode pengukuran. Badan Pertanahan Nasional melalui petunjuk teknisnya membagi metode pengukuran menjadi empat. Di antara keempat metode tersebut yang akan digunakan pada penelitian ini adalah metode terestrial dan pengamatan satelit. Penelitian ini bertujuan untuk menganalisis hasil pengukuran pengamatan satelit menggunakan teknologi CORS-NTRIP dan PPP yang akan dibandingkan dengan metode terestrial. Simulasi pengukuran dilakukan pada empat jenis bidang tanah, yaitu kebun, lapangan, sawah, dan perumahan. Dari hasil simulasi tersebut disimpulkan bahwa salah satu hal yang mempengaruhi letak dan luas bidang tanah adalah ruang pandang receiver terhadap langit. Dari penelitian ini direkomendasikan agar pengukuran bidang tanah dapat dilakukan dengan menggunakan metode kombinasi.
\end{abstract}

Kata kunci: bidang tanah, GNSS, CORS, NTRIP, PPP

\begin{abstract}
The need for land and space utilization is increasing every year. To control these needs, it is necessary to provide a certificate of land parcels. The procurement of the certificate is closely related to the measurement method. The National Land Agency, through its technical guidance, divides the measurement method into four. Among the four methods, which will be used in this study are terrestrial methods and satellite observations. The purpose of this study was to analyze the results of satellite observation measurements using CORS-NTRIP and PPP technologies that would be compared with terrestrial methods. The measurement simulation has been carried out by four types of parcels, ie. farm, open area, rice field, and building area. From the simulation results, it is concluded that one of the things that affect the location and the area of land is the receiver's view of the sky. From this research, it is recommended that land parcels measurement should be done by using a combination method.
\end{abstract}

Key words: land parcel, GNSS, CORS, NTRIP, PPP 


\section{PENDAHULUAN}

Sejak dimulainya pendaftaran tanah secara sistematik tahun 1960 hingga tahun 2008 terdapat 39.023.491 bidang tanah yang telah memiliki sertifikat (Abidin dkk., 2012). Percepatan pengukuran dan pemetaan bidang tanah menjadi penting karena kebutuhan akan tanah dan ruang yang semakin strategis. Pemanfaatan tanah dan ruang juga akan terkendali jika sertifikat bidang tanah tersedia, mengingat jumlah penduduk yang semakin meningkat setiap tahun.

Pengadaan sertifikat erat kaitannya dengan metode pengukuran yang digunakan. Menurut Petunjuk Teknis Badan Pertanahan Nasional (BPN) tahun 1997, metode pengukuran dibagi menjadi empat, yaitu terestrial, fotogramteris, pengamatan satelit, dan kombinasi. Metode pengamatan satelit yang telah digunakan BPN adalah Continuosly Operating Reference Station-Network Transport of RTCM via Internet Protocol (CORS-NTRIP). Sejak ditetapkan pada tahun 2009, hingga tahun 2014 telah tersebar 183 stasiun referensi permanen dengan jarak \pm 30-70 km di seluruh Indonesia. Menurut Gordini dkk. (2006), ketelitian teknologi ini dapat mencapai $1-5 \mathrm{~cm}$. Teknologi lainnya yang disebutkan pada petunjuk teknis BPN adalah Precise Point Positioning. Teknologi ini dapat memberikan ketelitian secara real-time hingga $\pm 4 \mathrm{~cm}$ (Leandro dkk., 2012). Menurut Alkan dkk. (2016) teknologi ini dapat menghapus kebutuhan akan stasiun referensi permanen karena hanya menggunakan single receiver. Pada penelitian ini koreksi real-time diberikan melalui satelit L-Band. Berdasarkan pada keunggulan dua teknologi tersebut maka perlu dilakukan simulasi pengukuran pada beberapa bidang tanah. Penelitian ini bertujuan untuk menganalisis hasil pengukuran CORSNTRIP dan PPP yang akan dibandingkan dengan metode terestrial. Mengacu pada petunjuk teknis BPN terkait hasil pengukuran dan pemetaan bidang tanah maka analisis yang akan dibahas pada penelitian ini terkait letak dan luas bidang tanah yang dihasilkan teknologi tersebut.

Data yang digunakan pada penelitian ini merupakan data hasil pengukuran bidang tanah di lapangan. Receiver yang digunakan untuk teknologi CORS-NTRIP adalah GEO XH 6000 Series Handhelds, sementara PPP menggunakan receiver GNSS Trimble NETR9. Simulasi pengukuran bidang tanah dilakukan pada beberapa jenis bidang tanah, yaitu: sawah, lapangan, kebun, dan pemukiman. Penelitian ini diharapkan dapat bermanfaat sebagai kajian ilmiah terkait pengaplikasian metode pengamatan satelit, terutama teknologi CORS-NTRIP dan PPP dalam pengukuran bidang tanah untuk dapat memberikan rekomendasi terkait penggunaan kedua teknologi dalam pengukuran bidang tanah.

\section{METODOLOGI PENELITIAN}

Penelitian ini diawali dengan menentukan lokasi simulasi pengukuran bidang tanah. Dalam penentuan lokasi ini, titik batas bidang tanah ditandai dengan menggunakan patok. Setiap bidang tanah yang sudah didefinisikan titiknya diukur menggunakan metode penentuan posisi horizontal dengan ETS pada jaring poligon tertutup. Titik ikat untuk jaring poligon ini didapatkan dari hasil pengamatan satelit. Koordinat pada jaring poligon yang diukur menggunakan ETS digunakan sebagai referensi di mana nilai-nilai koordinat yang dihasilkan dianggap benar.

Simulasi pengukuran bidang tanah akan dilakukan pada beberapa jenis bidang tanah, yaitu sawah, lapangan, kebun, dan pemukiman (Gambar 1) dengan ruang pandang yang bervariasi untuk melihat pengaruhnya terhadap metode pengamatan satelit yang bergantung 
pada ruang pandang terhadap langit sehingga dapat dianalisis pengaruhnya terhadap hasil pengukuran.

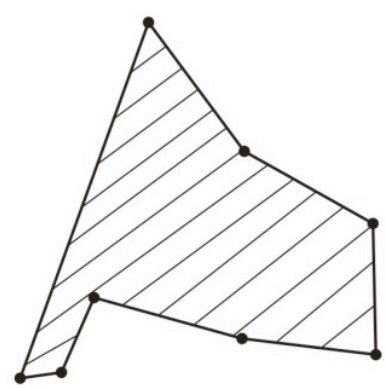

Kebun

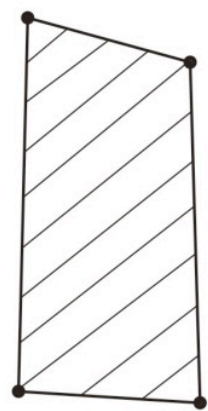

Lapangan

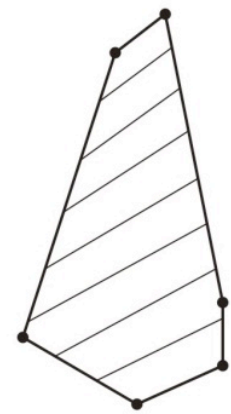

Sawah

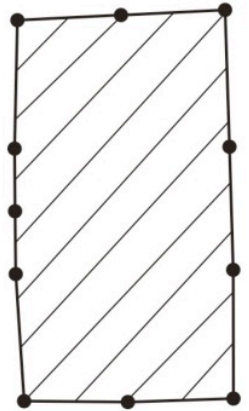

Perumahan

\section{Gambar 1. Geometrik Pengukuran}

Ruang pandang terhadap langit mempengaruhi jumlah satelit yang ditangkap oleh receiver yang efeknya secara langsung mempengaruhi kualitas penentuan posisi pengamatan satelit (Han dkk., 2012). Variasi medan permukaan bumi juga mempengaruhi daerah tangkapan satelit. Sebagai contoh, pengambilan data pada daerah pemukiman membuat receiver tidak dapat menangkap satelit dengan baik karena adanya gangguan ruang pandang. Ilustrasi mengenai ruang pandang yang dipengaruhi medan permukaan bumi dapat dilihat pada Gambar 2. Untuk mengetahui sudut obstruksi maksimum di bidang tanah yang akan diteliti dilakukan dengan menggunakan ETS sehingga bidang tanah yang dipilih mewakili variasi ruang pandang yang akan diteliti.

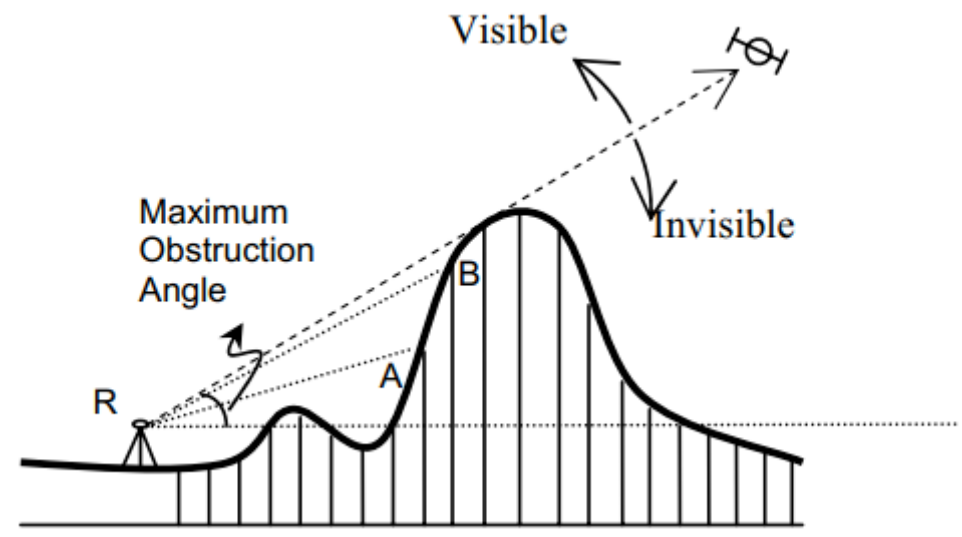

Gambar 2. Ruang Pandang yang dipengaruhi Medan Permukaan Bumi (Han dkk., 2012)

Receiver yang digunakan untuk teknologi CORS-NTRIP adalah GEO XH 6000 Series Handhelds, sementara PPP menggunakan receiver GNSS Trimble NETR9. Data pengukuran yang didapatkan dari teknologi CORS-NTRIP dan PPP tidak diolah kembali karena data tersebut telah terkoreksi secara real-time. Data CORS-NTRIP dan PPP berupa nilai koordinat beserta ketelitiannya.

Hasil pengukuran seluruh metode kemudian di-plotting untuk mengetahui letak bidang tanah dan dihitung luas bidang tanahnya. Analisis pada penelitian ini fokus pada ketelitian letak dan luas bidang tanah. Perbedaan letak bidang tanah akan diperoleh dari selisih koordinat 
dari nilai yang dianggap benar dengan masing-masing metode pengamatan satelit yang dinyatakan dengan nilai absolut. Selisih nilai $\mathrm{x}(\Delta \mathrm{x})$ dan nilai $\mathrm{y}(\Delta \mathrm{y})$ kemudian dihitung resultannya ( $r$ ) dengan Persamaan 1.

$$
r=\sqrt{(\Delta x)^{2}+(\Delta y)^{2}}
$$

Untuk mengetahui apakah perbedaan letak bidang tanah ini secara statistik signifikan atau tidak maka dilakukan uji statistik terhadap nilai rata-rata resultan di setiap lokasi. Uji statistik dilakukan dengan menggunakan uji parameter dengan tingkat signifikansi uji satu arah sebesar 5\% (Boediono dan Koster, 2008). Hipotesis yang digunakan untuk semua posisi bidang tanah menggunakan Persamaan 2-5.

$$
\begin{aligned}
& \mathrm{H}_{0}: \overline{\mathrm{X}_{1}}=\overline{\mathrm{X}_{2}} \\
& \frac{\overline{\mathrm{X}_{1}}-\overline{\mathrm{X}_{2}}}{\sqrt{\sigma_{1}^{2}+\sigma_{2}^{2}}}<\mathrm{t}_{\mathrm{\alpha}, \mathrm{df}}, \text { maka hipotesis diterima } \\
& \mathrm{H}_{0}: \overline{\mathrm{X}_{1}} \neq \overline{\mathrm{X}_{2}} \\
& \frac{\overline{\mathrm{X}_{1}}-\overline{\mathrm{X}_{2}}}{\sqrt{\sigma_{1}^{2}+\sigma_{2}^{2}}}>\mathrm{t}_{\mathrm{a}, \mathrm{dt}}, \text { maka hipotesis ditolak }
\end{aligned}
$$

dimana, hipotesis nol $\left(\mathrm{H}_{0}\right)$ diterima jika nilai hasil uji yang dihitung dengan menggunakan nilai rata-rata resultan $\left(\overline{\mathrm{X}_{1}}\right.$ dan $\left.\overline{\mathrm{X}_{2}}\right)$ dan variansi setiap nilai rata-rata $\left(\sigma_{1}^{2}\right.$ dan $\left.\sigma_{2}^{2}\right)$ lebih kecil dari taraf ujinya. Sebaliknya, hipotesis nol ditolak jika hasil uji lebih besar dari taraf ujinya.

Keempat jenis bidang tanah dan hasil pengukurannya kembali diolah untuk menghitung nilai luas bidang tanahnya. Luas bidang tanah dhitung dengan menggunakan Persamaan 6.

$$
L=\frac{\left(X_{1} Y_{2}+X_{2} Y_{3}+\cdots+X_{n} Y_{1}\right)-\left(Y_{1} X_{2}+Y_{2} X_{3}+\cdots+Y_{n} X_{1}\right)}{2}
$$

dimana, $L$ adalah luas bidang tanah, $X_{1}$ hingga $X_{n}$ dan $Y_{1}$ hingga $Y_{n}$ adalah nilai koordinat dari titik-titik yang ada pada bidang tanah.

Secara garis besar penelitian ini dilakukan dengan tahapan seperti pada Gambar 3. 


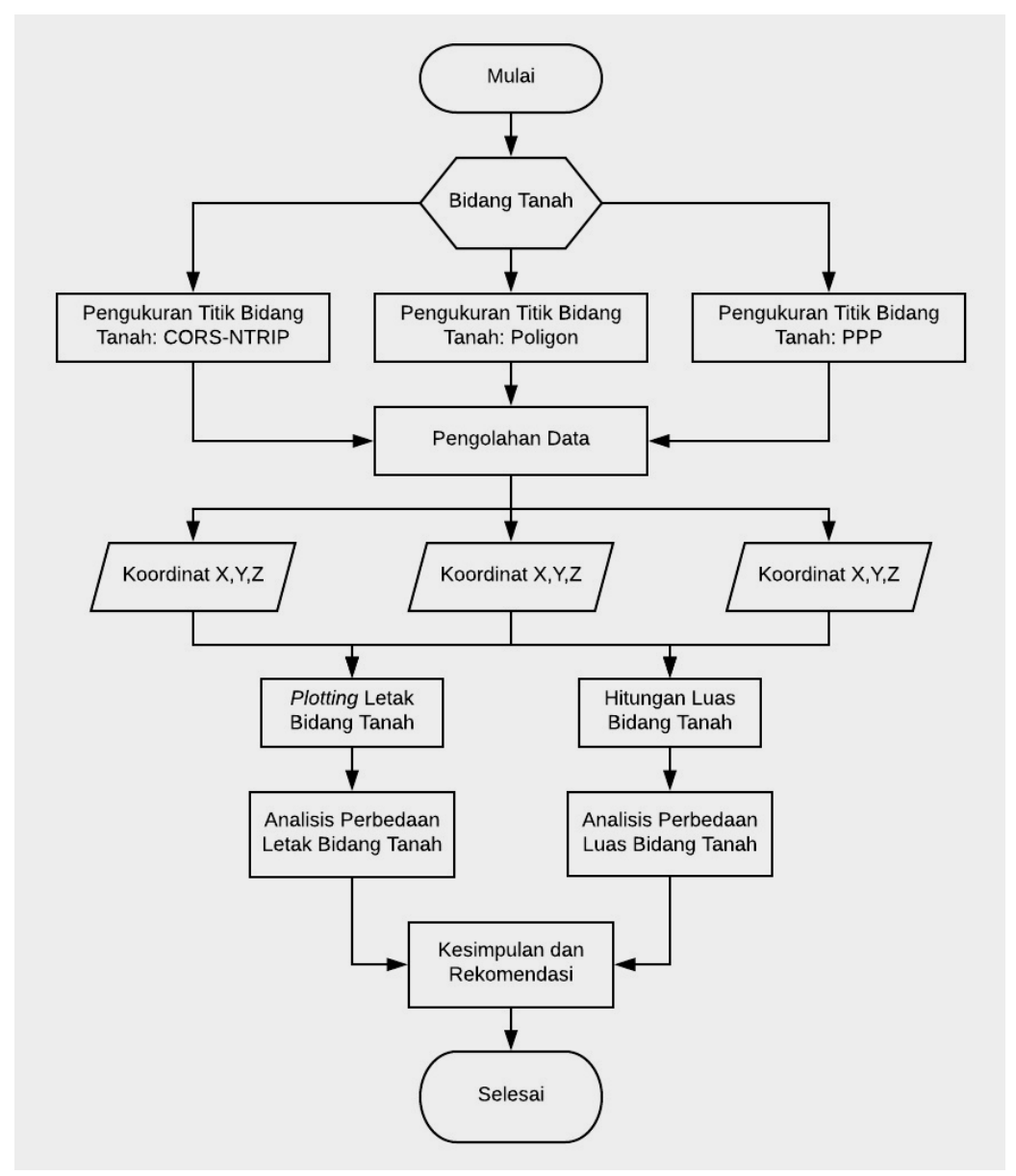

\section{Gambar 3. Metodologi Penelitian}

\section{HASIL DAN ANALISIS}

Pengukuran yang dilakukan penggunakan metode terestris dan metode pengamatan satelit pada empat jenis bidang tanah menghasilkan letak seperti pada Gambar 4. Gambar tersebut memperlihatkan letak bidang tanah yang diukur menggunakan metode pengamatan satelit umumnya bergeser dari posisi yang dianggap benar (dari hasil pengukuran metode terestris menggunakan ETS). Perbedaan letak ini dipengaruhi oleh beberapa hal, salah satunya adalah ruang pandang receiver terhadap langit.

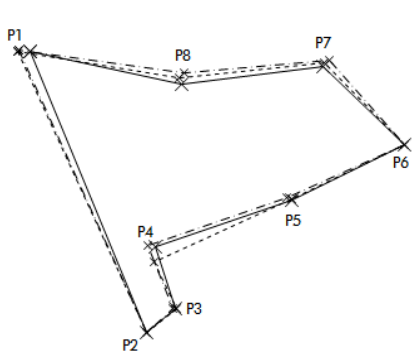

(1)

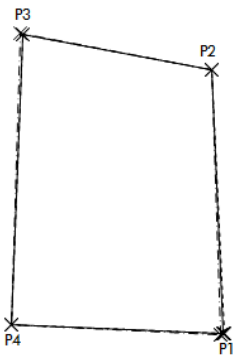

(2)

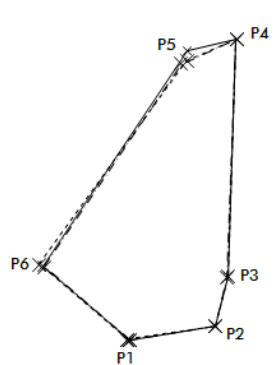

(3)

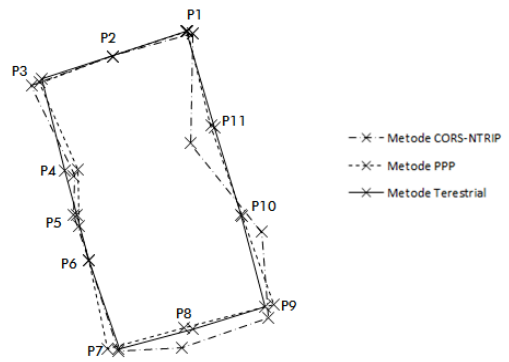

(4)

Gambar 4. Penempatan Titik Hasil Pengukuran Bidang Tanah: (1) Kebun, (2) Lapangan, (3) Sawah, dan (4) Perumahan 
Pada Gambar 4 dapat dilihat bidang tanah 2 dan 3 yang merupakan lapangan dan sawah tidak terlalu memiliki perbedaan letak. Kedua bidang ini memiliki ruang pandang yang terbuka. Dalam penggunaan metode pengamatan satelit kondisi ini menurut Han dkk. (2012) akan memberikan hasil dengan kualitas lebih baik karena tidak terhalangnya tangkapan sinyal satelit. Jumlah satelit yang diperoleh CORS-NTRIP lebih kurang sepuluh satelit dan PPP memperoleh lebih kurang 14 satelit. Berbeda halnya dengan bidang 1 dan 4 yang merupakan kebun dan perumahan. Dari hasil penempatan titik yang ditampilkan pada grafik resultan pada Gambar 5 dapat dilihat bahwa bidang 1 dan 4 mengalami perbedaan letak yang cukup besar. Lokasi 1 pada titik P4 yang menggunakan teknologi PPP memiliki perbedaan letak hingga 5,196 meter. Pada titik ini ruang pandang yang tertutup mengakibatkan titik ini hanya memiliki ketelitian 1,702 meter dengan status autonomous yang berarti bahwa titik P4 tidak mendapatkan koreksi secara real-time.
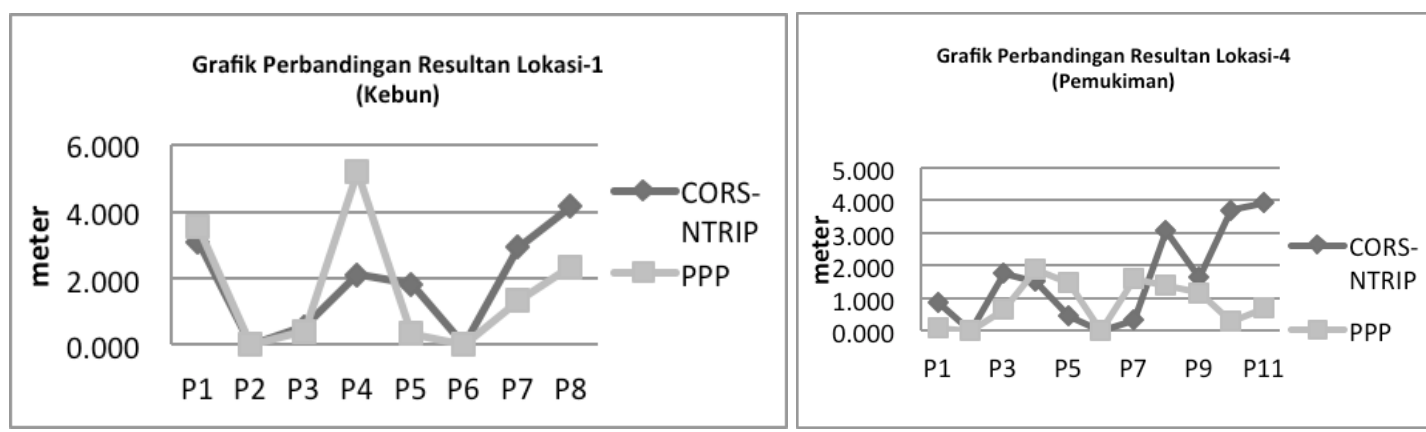

Gambar 5. Grafik Perbandingan Resultan Bidang Tanah 1 dan 4

Pada bidang 4 yang menggunakan teknologi CORS-NTRIP terjadi perbedaan letak cukup besar. Salah satu titik yang pergeserannya paling besar adalah titik P8 dengan nilai 3,070 m. Titik P8 merupakan salah satu titik yang memiliki ruang pandang yang sangat tertutup, sehingga kemungkinan terjadinya multipath cukup besar yang akan mempengaruhi hasil ketelitian letak bidang tanah yang diukur.

Berdasarkan perbandingan resultan bidang tanah 1 dan 4 seperti pada Gambar 5 maka akan diuji apakah perbedaan tersebut dapat diterima atau tidak secara statistik. Berdasarkan hipotesisnya maka hasil uji statistiknya dapat dilihat pada Tabel 1.

Tabel 1. Uji Statistik Terhadap Nilai Rata-Rata Resultan

\begin{tabular}{|c|c|c|c|c|c|c|c|c|c|}
\hline \multirow{2}{*}{ No. } & \multicolumn{2}{|c|}{$\begin{array}{l}\text { Rata-rata }(\overline{\mathrm{X}}) \\
\text { dalam meter }\end{array}$} & \multicolumn{2}{|c|}{$\begin{array}{c}\text { Variansi }\left(\sigma^{2}\right) \\
\text { dalam } \mathrm{m}^{2}\end{array}$} & \multirow{2}{*}{$\begin{array}{l}\text { Derajat } \\
\text { Kebebasan } \\
\text { (df) }\end{array}$} & \multirow{2}{*}{$\begin{array}{c}\text { Taraf } \\
\text { Uji } \\
\left(\mathrm{t}_{\mathrm{a}, \mathrm{df}}\right)\end{array}$} & \multirow{2}{*}{$\begin{array}{c}\text { Hasil } \\
\text { Uji }\end{array}$} & \multirow{2}{*}{ Keterangan } & \multirow{2}{*}{$\begin{array}{l}\text { Bidang } \\
\text { Tanah }\end{array}$} \\
\hline & $\begin{array}{l}\text { CORS- } \\
\text { NTRIP }\end{array}$ & PPP & $\begin{array}{l}\text { CORS- } \\
\text { NTRIP }\end{array}$ & PPP & & & & & \\
\hline 1 & 1,818 & 1,645 & 2,350 & 3,623 & 14 & 1,761 & 0,071 & Diterima & Bidang 1 \\
\hline 2 & 0,266 & 0,030 & 0,103 & 0,001 & 6 & 1,943 & 0,732 & Diterima & Bidang 2 \\
\hline 3 & 0,627 & 0,618 & 1,374 & 0,749 & 10 & 1,812 & 0,006 & Diterima & Bidang 3 \\
\hline 4 & 1,576 & 0,845 & 2,069 & 0,493 & 20 & 1,725 & 0,457 & Diterima & Bidang 4 \\
\hline
\end{tabular}

Berdasarkan Tabel 1 didapati bahwa semua perbedaan letak bidang tanah masih dapat diterima secara statistik. Dapat disimpulkan bahwa kedua teknologi ini tidak memiliki 
perbedaan yang signifikan antara satu dan lainnya. Perbedaan letak ini juga masih dapat diterima walau posisinya bergeser dari pengukuran yang dianggap benar.

Selain ruang pandang jumlah satelit juga dipengaruhi oleh mask angle. Mask angle adalah sudut yang dibentuk oleh arah mendatar receiver terhadap orbit satelit yang sudah telah ditentukan besarannya. Semakin kecil nilai mask angle (a) yang dipergunakan berarti akan semakin banyak jumlah satelit yang diperoleh. Sebaliknya, semakin besar nilai a, maka akan mempersempit area tangkapan satelit (Heng, 2015). Mask angle yang digunakan saat penelitian adalah sebesar $15^{\circ}$. Pengaruh jumlah satelit terhadap ketelitian letak bidang tanah tidak terlalu berpengaruh pada teknologi CORS-NTRIP. Baik itu lokasi dengan ruang pandang terbuka maupun tertutup, kisaran satelit yang diperoleh sebanyak 9-11 satelit. Hal ini berbeda pada penggunaan teknologi PPP, untuk ruang pandang terbuka seperti pada bidang 2 dan 3 jumlah yang diperoleh hingga 16 satelit. Lain halnya lokasi dengan ruang pandang tertutup, contohnya pada bidang 4 (perumahan), hanya diperoleh 5 buah satelit. Dapat dilihat pada Gambar 5 bahwa ruang pandang berpengaruh pada penggunaan teknologi PPP, tetapi tidak dengan teknologi CORS-NTRIP.

Luas bidang tanah dihitung dengan menggunakan nilai koordinat dari hasil pengamatan metode terestrial dan pengamatan satelit. Dari hasil hitungan luas bidang tanah diperoleh nilai selisih luas anatara metode terestrial-CORS NTRIP dan metode terestrial-PPP. Menurut petunjuk teknis yang dikeluarkan oleh (Badan Pertanahan Nasional, 1997) selisih luas bidang tanah yang diperbolehkan adalah memenuhi toleransi $2 \%$. Hasil hitungan luas bidang tanah dapat dilihat pada Tabel 2.

Tabel 2. Hitungan Luas Bidang Tanah Seluruh Lokasi

\begin{tabular}{ccccccccc}
\hline \hline \multirow{2}{*}{ No. } & \multicolumn{1}{c}{ Luas $\left(\mathrm{m}^{2}\right)$} & \multicolumn{5}{c}{ Selisih Luas $\left(\mathrm{m}^{2}\right)$} \\
& NTRIP & ETS & PPP & ETS-CORS & ETS-PPP & Bidang Tanah \\
\hline \hline 1 & 4482,234 & 4402,535 & 4614,645 & 79,699 & 1,8 & 212,109 & 4,8 & Bidang 1, kebun \\
\hline 2 & 1625,277 & 1647,996 & 1646,180 & 22,719 & 1,4 & 1,816 & 0,1 & Bidang 2, lapangan \\
\hline 3 & 1425,492 & 1425,988 & 1423,988 & 0,496 & 0,0 & 2,000 & 0,1 & Bidang 3, sawah \\
\hline 4 & 836,773 & 849,352 & 825,852 & 12,578 & 1,5 & 23,500 & 2,8 & Bidang 4, pemukiman \\
\hline \hline
\end{tabular}

Dari Tabel 2 terlihat bahwa yang tidak memenuhi toleransi adalah pengukuran yang dilakukan menggunakan teknologi PPP pada bidang tanah 1 dan 4. Seperti yang sudah dibahas sebelumnya bahwa kedua lokasi ini memiliki ruang pandang yang terbatas yang berpengaruh pada selisih luas yang dihasilkan PPP. Akan tetapi, walaupun seluruh luas bidang tanah yang dihasilkan CORS-NTRIP memenuhi toleransi, tetapi dapat dilihat pada letaknya, masih tidak sesuai dengan penggambaran bidang tanah yang dianggap benar.

\section{KESIMPULAN}

Berdasarkan hasil dan analisis yang diperoleh dari pengukuran menggunakan teknologi CORS-NTRIP dan PPP yang diaplikasikan pada pengukuran bidang tanah, maka diperoleh beberapa kesimpulan. Terdapat perbedaan letak bidang tanah pada bidang 1 (kebun) dan bidang 4 (pemukiman). Perbedaan ini dipengaruhi oleh ruang pandang pada tiap-tiap lokasi yang didominasi oleh ruang pandang yang tertutup. Secara statistik letak bidang tanah yang 
dihasilkan CORS-NTRIP dan PPP tidak memiliki perbedaan yang signifikan. Selisih luas bidang tanah yang dihasilkan PPP pada bidang 1 dan 4 tidak memenuhi toleransi yang diajukan (Badan Pertanahan Nasional, 1997), yaitu sebesar 2\%, sementara itu selisih luas bidang tanah yang dihasilkan CORS-NTRIP masih memenuhi toleransi.

Dari kesimpulan yang diperoleh maka dari penelitian ini terdapat beberapa rekomendasi terkait pengukuran bidang tanah. Pengaplikasian teknologi CORS-NTRIP dan PPP pada pengukuran bidang tanah sebaiknya dikombinasikan dengan metode terestrial. Penggunaan teknologi CORS-NTRIP dan PPP masih belum dapat dipergunakan secara penuh pada pengukuran bidang tanah. Teknologi CORS-NTRIP dan PPP dapat digunakan untuk membantu penyediaan titik dasar teknik secara virtual dan sebagai titik orientasi pengukuran agar memudahkan dalam proses plotting pada peta pendaftaran.

\section{UCAPAN TERIMA KASIH}

Ucapan terimakasih yang sebesar-besarnya disampaikan kepada PT GPSLands Indosolutions sebagai penyedia alat untuk penelitian ini.

\section{DAFTAR PUSTAKA}

Abidin, H.Z., Haroen, T.S., Mudita, I., dan Adiyanto, F.H. (2012). Implementation of GPS CORS for Cadastral Survey and Mapping in Indonesia: Status, Constraints, and Opportunities. FIG Working Week 2012, Italy.

Alkan, R.H., Ozulu, I.M., dan Ilci, V. (2016). Precise Point Positioning versus Network-RTK GNSS. FIG Working Week 2016. New Zealand.

Badan Pertanahan Nasional. (1997). Petunjuk Teknis Peraturan Menteri Negara Agraria/ Kepada Badan Pertanahan Nasional No. 3 Tahun 1997 Tentang Materi Pengukuran dan Pemetaan Pendaftaran Tanah. Jakarta

Boediono dan Koster, W. (2008). Teori dan Aplikasi Statistika dan Probabilitas. Bandung: PT. Remaja Rosdakarya.

Gordini, C., Kealy, A. N., Grgich, B. M., dan Hale, M. J. (2006). Testing and Evaluation of a GPS CORS Network for Real Time Centimetric Positioning - The Victoria GPSNet ${ }^{T M}$. International Global Navigation Satellite System (IGNSS) Symposium 2006, Australia.

Han, J., Wu, Y., dan Liu, R. (2012). Determining the Optimal Site Location of GNSS Base Stations. Boletim de Ciências Geodésicas, 18(1), 154-169.

Heng, L., Walter, T., Enge, P., dan Gao, X.G. (2015). GNSS Multipath and Jamming Mitigation using High Mask Angle Antennas and Multiple Constellations. IEEE Transactions on Intelligent Transportation Systems, Volume: 16, Issue: 2, 741-750. 